\title{
Effect of low-temperature plasma on forage maize ( Zea mays Linn.) seeds germination and characters of the seedlings
}

\author{
Changyong Shao ${ }^{1,4, a}$ Decheng Wang ${ }^{1,5 *}$ Xianfa Fang $^{2}$ Xin Tang ${ }^{3}$ Lijing Zhao ${ }^{4}$ Lili Zhang ${ }^{4}$ \\ Liangdong Liu $^{1} \quad$ Guanghui Wang ${ }^{1}$ \\ ${ }^{1}$ College of Engineering, China Agricultural University, Beijing, 10083, China \\ ${ }^{2}$ Chinese Academy of Agriculture Mechanization Sciences, Beijing, 10083, China \\ ${ }^{3}$ Shandong Agricultural And Engineering College, Jinan, 250100, China \\ ${ }^{4}$ Shandong Province Seeds Group Co., Ltd, Jinan, 250100, China \\ ${ }^{5}$ Key Lab of Soil-Machine-Plant System of Chinese Agriculture Ministry, Beijing, 100083, China \\ a shaochangyong68@163.com
}

\begin{abstract}
Low-temperature plasma is a high-energy state of the material gathered. Plasma seed processing technology is the use of high energy aggregation on treating crop seeds within 20 seconds. Previous research elucidated that this technology could improve germination and seedling growth of welsh onion seeds. In this paper, the effects of different intensities of low-temperature plasma on forage maize seeds have been investigated. The vigor and rate of germination, length of root and shoot of seedlings, the green and dry weight, and the fiber root number of seedlings of the treated sample seeds were compared with those of untreated seeds. The results showed substantial changes in the vigor and rate of germination just like what we found in welsh onion seeds. Thus, the characters of seedlings change regularly with the intensity of low-temperature plasma, and the analysis indicated that $120 \mathrm{~W}$ was the optimum treatment. Results showed that low-temperature plasma was effective in improving seedling growth, we believe it will be also effective in earlier flowering and maturity and higher yield. There is a great value of using and spreading on production.
\end{abstract}

Key words: Low-temperature plasma; forage maize seeds; characters of seedlings

\section{Introduction}

Besides the 'traditionally' known solid state, liquid and gas phase and the more recently found low-temperature states (BOSE-EINSTEIN condensate), high-temperature states, such as plasmas existing. Although the generation of a plasma from the gas phase (Figure 1) isn't strictly spoken to be a real phase transition, plasma was recognized as the 4th state of matter due to its distinct properties, which substantially discriminated it from the gas phase[1].

\footnotetext{
* corresponding author.
} 


\section{States of Matter}

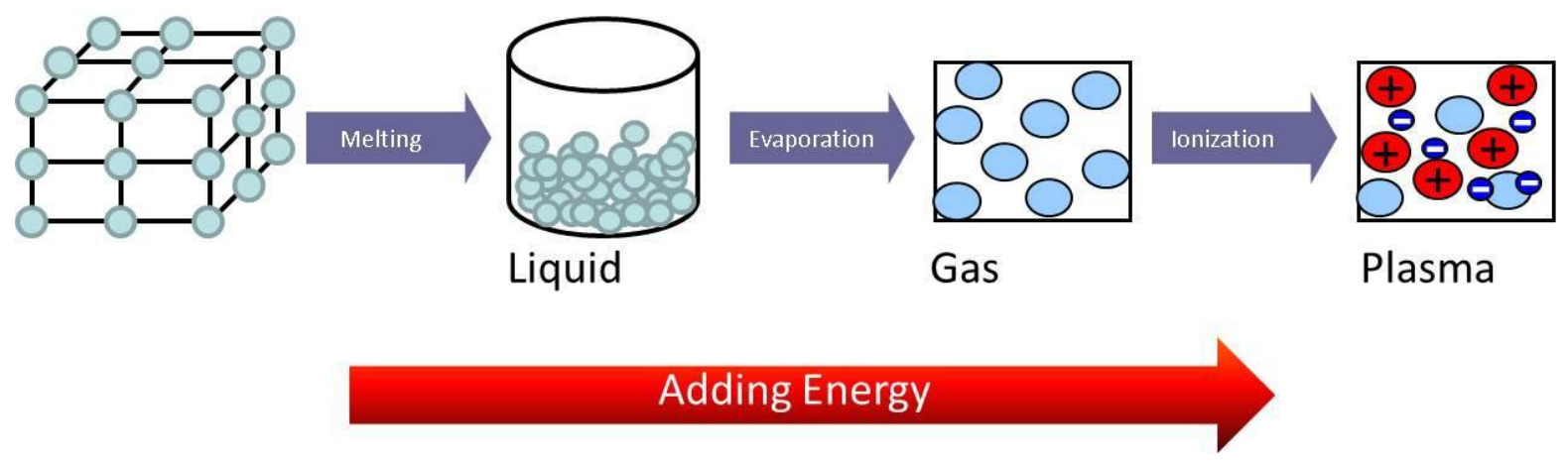

Fig.1. Four states of matter. Plasma is characterized by a collective behavior of its free charge carriers. (Franziska

Grzegorzewski, 2010)

Physical agriculture is the application of physical methods in agriculture and has been studied since the 1970s[2]. Low-temperature plasma (LTP) is an application of physical agriculture. Yin (2006) reported that LTP was utilized in biological applications in Russia[3]. There has been some research in LTP seed processor comprising a plasma generator was used to treat seeds in Russia and CIS countries (Li, 2010). Similar reports exist in America and Canada[4]. Stimulation of plants with a plasma field to promote seed germination and increase yield quantities and quality has attracted interest worldwide, with remarkable achievements reported in Japan[5]. At present, abroad study shows that both ionizing radiations, and even mass loading effect and exchange of charge are existing in LTP field. This field activated endogenous substances in the seeds, leading to improvements in the rate of seed germination, crop resistance and crop yield and an earlier maturity date[6-11].

Zea mays Linn., maize or corn, is one of the major cereals of the world and is the third largest field crop. Various kinds of technology have been used on maize seeds processing to promote germination and increase yield, such as magnetization and plasma[12-13].Our study focuses on the influence of LTP treatment on maize seeds in terms of the seed germination and biological characters of seedlings.

\section{Materials and Methods}

\subsection{Experimental set-up}

The equipment used in this study was provided by ChangZhou ZhongKe ChangTai Plasma Technology Co. and 
the device worked under the vacuum state. This machine can be carried out with large capacity in a continuous or batch process.

\subsection{Sample seeds}

Tests were carried out both in laboratory and field conditions with LUZHONG 99118 maize seeds (selected by Shandong Province Seeds Group Co., LTD). This variety is food and fodder dual-purpose maize. There still have 12 to 13 green leaves when maturing, suit to be used as silage.

\subsection{Experimental design}

\subsubsection{Test media}

Laboratory plasmas can be generated by supplying energy to a kind of neutral gas. Electrical discharges are the most common for generating non-thermal plasmas. Neon is colorless and odorless inert gases. Neon conducts electricity 75 times better than air. The test result indicates a uniform stable glow discharge has been obtained between two planar electrodes when using neon as test media. Therefore, neon was used as media in our experiment.

\subsubsection{LTP treatment}

Healthy and uniform maize seeds were treated with various plasma strengths $(0,60,80,100,120,140,160,180$, 200W). 1 kilogram of maize seeds was used in each treatment.

\subsubsection{Germination tests and analysis of the germination rate, vigor}

The germination tests were started on the 16th, 30th, 45th, 60th, 75th, 90th, 120th, 150th days after seeds treated by LTP. Each treatment was repeated four times to confirm the repeatability of the results, with 100 seeds for every repetition.

After treatment, the seeds were allowed to germinate in sand bed under laboratory. During the experiments, water was added to the sand bed to guarantee sufficient moisture for germination. The incubation temperature was $25^{\circ} \mathrm{C}$.

A seed was considered germinated if both the radicle and coleoptile length were $\geqslant 2 \mathrm{~mm}$. Seedlings were counted at 24-h intervals up to 7 days. The germination vigor is used to assess the quality of field emergence and is defined as the percentage of seeds that germinate within a short time (4 days after lined for maize according to GB/T 3543.4-1995, Rules for Agricultural Seed Testing-germination test). The germination rate is defined as the 
percentage of seeds that germinate in a specified time ( 7 days after lined for maize according to GB/T 3543.4-1995). These are calculated as follows:

Vigor of germination $(\%)=($ Number of seeds germinated in 4 days/total number of seeds $) \times 100$

Rate of germination $(\%)=($ Number of seeds germinated in 10 days/total number of seeds $) \times 100$

\subsubsection{Investigation on biological characters of maize seedlings in laboratory}

On the 7th day of germination experiment, ten seedlings of each repetition were randomly selected and the length of shoot \& root, green \& dry weight of these seedlings were investigated. Length of shoot is defined as the length between the mesocotyl and tip of seedlings. Length of root is defined as the length between the mesocotyl and the root tip.

Samples used in this experiment were kept in a cool dry place for 90 days after treated by LTP. Also, both the green and dry weight of seedlings were measured.

\subsubsection{Investigation on biological characters of maize seedlings in field}

In 90 days after treated by LTP, seeds were sowed in field. Ten days later. Ten seedlings of each repetition were randomly selected and the length of shoot \& root, fiber root number were investigated.

\section{Results and Discussion}

This experiment was conducted to assess the influence of different intensities of LTP on seed germination and early growth, also the aging effect of this influence was investigated. The data of germination vigor for maize seeds are listed in Table 1, and the data of germination rate are listed in Table 2.

The optimum intensity of samples in different times after LTP treated is fugitive. But for each samples, we can both have the maximal vigor and rate in one certain intensity.

The effect of LTP on vigor and rate of maize seeds germination changed with time. LTP played an active role in seed germination within 16 days. And it dropped the seed germination rate and vigor during 30-120 days, 150 days after treated, and this inhibition had been weak.

Table 3 showed the shoot and root length of seedlings under lab condition, and the shoot \& root length and fiber root number of seedlings in field were lined in table 4. The green and dry weight of seedlings in field were listed in table 5 . 
Table 1. Vigor of germination of forge maize seeds stimulated by low-temperature plasma $(\%)$

\begin{tabular}{|c|c|c|c|c|c|c|c|c|c|c|}
\hline Intensity of & $0(\mathrm{ck})$ & 60 & 80 & 100 & 120 & 140 & 160 & 180 & 200 & \\
\hline 16 & $81 \mathrm{~b}$ & $88 \mathrm{a}$ & $89 a$ & $91 \mathrm{a}$ & $91 \mathrm{a}$ & $91 \mathrm{a}$ & $88 \mathrm{a}$ & $88 \mathrm{a}$ & $87 a$ & $87.83 \mathrm{ab}$ \\
\hline 30 & $82 \mathrm{~d}$ & $86 \mathrm{bcd}$ & $86 \mathrm{bc}$ & $87 \mathrm{bc}$ & $90 \mathrm{abc}$ & $90 \mathrm{abc}$ & $92 \mathrm{a}$ & $86 \mathrm{~cd}$ & $91 \mathrm{ab}$ & $88.06 \mathrm{ab}$ \\
\hline 45 & $81 \mathrm{~b}$ & $91 \mathrm{a}$ & $89 \mathrm{a}$ & $86 a$ & $89 a$ & $88 \mathrm{a}$ & $92 a$ & $90 \mathrm{a}$ & $87 a$ & $88.17 \mathrm{a}$ \\
\hline 60 & $81 \mathrm{~b}$ & $91 \mathrm{a}$ & $89 a$ & $89 a$ & $86 a$ & $86 a$ & $87 \mathrm{a}$ & $89 a$ & $87 a$ & $87.22 \mathrm{ab}$ \\
\hline 75 & $81 d$ & $88 \mathrm{abc}$ & $91 \mathrm{ab}$ & $92 a$ & $86 \mathrm{bc}$ & $86 c$ & $85 \mathrm{~cd}$ & $84 \mathrm{~cd}$ & $87 \mathrm{bc}$ & $86.44 b$ \\
\hline 90 & $80 \mathrm{c}$ & $89 a$ & $86 a b$ & $86 a b$ & $91 \mathrm{a}$ & $88 \mathrm{a}$ & $88 \mathrm{a}$ & $83 b c$ & $88 \mathrm{a}$ & $86.44 \mathrm{~b}$ \\
\hline 120 & $75 \mathrm{~d}$ & $80 \mathrm{~cd}$ & $81 \mathrm{bc}$ & $84 a b$ & $86 a$ & $80 \mathrm{bc}$ & $86 a$ & $81 \mathrm{bc}$ & $78 \mathrm{~cd}$ & $80.33 \mathrm{c}$ \\
\hline \multirow[t]{2}{*}{150} & $74 \mathrm{~cd}$ & $76 a b c$ & $75 \mathrm{bcd}$ & $79 a$ & $81 \mathrm{a}$ & $80 \mathrm{a}$ & $79 \mathrm{ab}$ & $81 \mathrm{a}$ & $71 d$ & $77.11 \mathrm{~d}$ \\
\hline & $78.94 \mathrm{e}$ & $85.5 \mathrm{bcd}$ & $85.75 \mathrm{abcd}$ & $87 a b$ & $87.38 \mathrm{a}$ & $86.13 \mathrm{abc}$ & $87.06 \mathrm{ab}$ & $84.81 \mathrm{~cd}$ & $84.25 \mathrm{~d}$ & I \\
\hline
\end{tabular}

Note: Columns with different lowercase letters: Low-temperature plasma treatment on Alexander Summer Squash bud potential, germination rate, significant differences in germination index $(\mathrm{P} \leqslant 0.05)$

Table 2. Rate of germination of forge maize seeds stimulated by low-temperature plasma (\%)

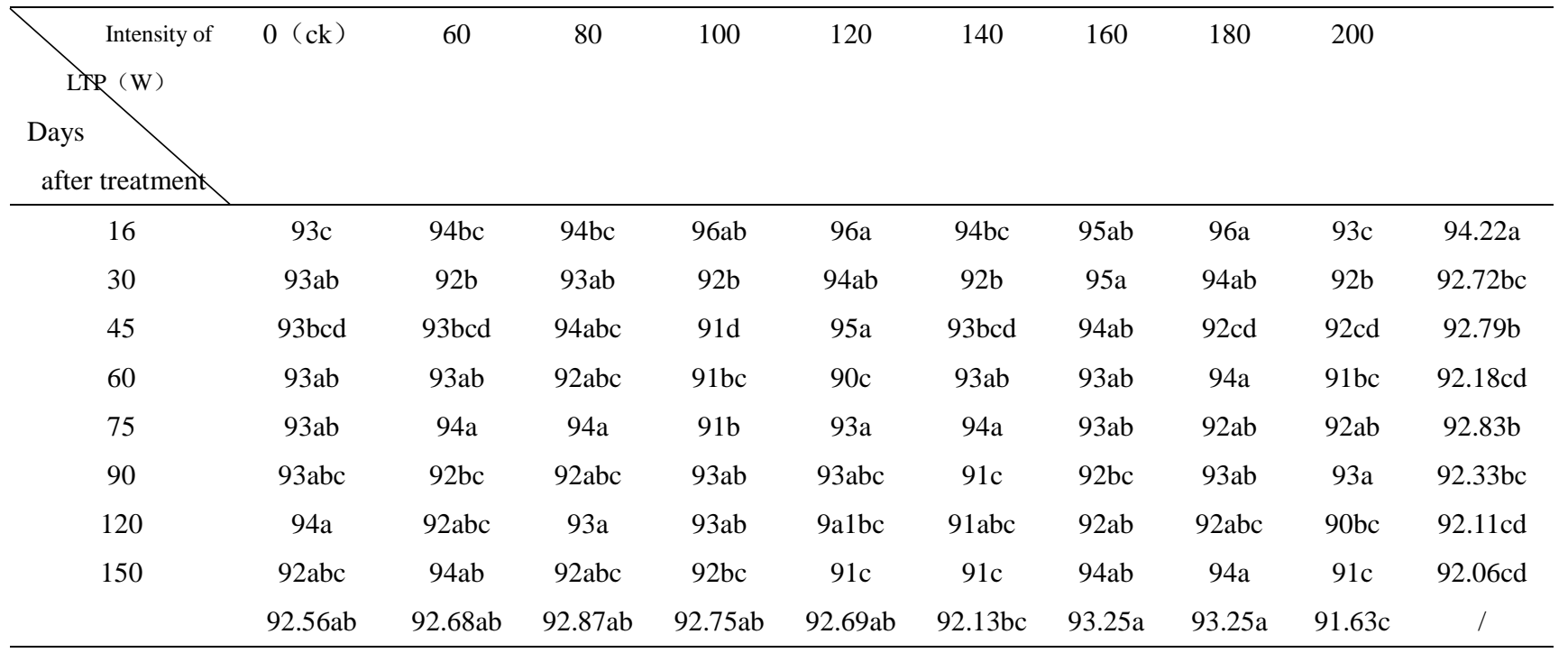

Note: Columns with different lowercase letters: Low-temperature plasma treatment on Alexander Summer Squash bud potential, germination rate, significant differences in germination index $(P \leqslant 0.05)$

Table 3. Length of shoot and root of seedlings under laboratory condition stimulated by low-temperature plasma (\%)

\begin{tabular}{lccccccccc}
\hline Intensity of LTP $(\mathrm{W})$ & $0(\mathrm{CK})$ & 60 & 80 & 100 & 120 & 140 & 160 & 180 & 200 \\
\hline Length of shoot $(\mathrm{cm})$ & $10.99 \mathrm{~cd}$ & $11.52 \mathrm{bc}$ & $12.04 \mathrm{ab}$ & $12.13 \mathrm{ab}$ & $12.3 \mathrm{a}$ & $11.50 \mathrm{bc}$ & $11.65 \mathrm{bc}$ & $11.36 \mathrm{~cd}$ & $10.74 \mathrm{~d}$ \\
Length of root $(\mathrm{cm})$ & $19.11 \mathrm{bc}$ & $19.55 \mathrm{abc}$ & $20.82 \mathrm{a}$ & $20.14 \mathrm{ab}$ & $19.33 \mathrm{bc}$ & $19.12 \mathrm{bc}$ & $19.40 \mathrm{bc}$ & $18.98 \mathrm{bc}$ & $18.19 \mathrm{c}$ \\
\hline
\end{tabular}

Note: Columns with different lowercase letters: Low-temperature plasma treatment on Alexander Summer Squash bud potential, germination rate, significant differences in germination index $(P \leqslant 0.05)$ 
Table 4. Length of shoot and root and fiber root number of seedlings under field condition stimulated by low-temperature plasma $(\%)$

\begin{tabular}{llllllllll}
\hline Intensity of LTP $(\mathrm{W})$ & $0(\mathrm{CK})$ & 60 & 80 & 100 & 120 & 140 & 160 & 180 & 200 \\
\hline Length of shoot $(\mathrm{cm})$ & $10.21 \mathrm{~cd}$ & $10.14 \mathrm{~d}$ & $10.33 \mathrm{~cd}$ & $11.42 \mathrm{ab}$ & $12.04 \mathrm{a}$ & $11.95 \mathrm{ab}$ & $11.62 \mathrm{ab}$ & $10.75 \mathrm{bc}$ & $11.03 \mathrm{ab}$ \\
& & & & $\mathrm{c}$ & & & $\mathrm{c}$ & $\mathrm{d}$ & $\mathrm{cd}$ \\
Length of root $(\mathrm{cm})$ & $31.04 \mathrm{a}$ & $36.55 \mathrm{a}$ & $35.53 \mathrm{a}$ & $34.57 \mathrm{a}$ & $33.05 \mathrm{a}$ & $33.04 \mathrm{a}$ & $36.07 \mathrm{a}$ & $36.9 \mathrm{a}$ & $35.01 \mathrm{a}$ \\
Fiber root number & $4.4 \mathrm{ab}$ & $4 \mathrm{~b}$ & $4.6 \mathrm{ab}$ & $4.75 \mathrm{ab}$ & $5 \mathrm{ab}$ & $5.2 \mathrm{a}$ & $4.6 \mathrm{ab}$ & $4.6 \mathrm{ab}$ & $4.5 \mathrm{ab}$ \\
\hline
\end{tabular}

Note: Columns with different lowercase letters: Low-temperature plasma treatment on Alexander Summer Squash bud potential, germination rate, significant differences in germination index $(\mathrm{P} \leqslant 0.05)$

Table 5. Green and dry weight of seedlings stimulated by low-temperature plasma (\%)

\begin{tabular}{llllllllll}
\hline Intensity of LTP (W) & 0 & 60 & 80 & 100 & 120 & 140 & 160 & 180 & 200 \\
\hline Green weight $(\mathrm{g})$ & $83.04 \mathrm{~cd}$ & $81.83 \mathrm{~d}$ & $85.77 \mathrm{~cd}$ & $91.62 \mathrm{ab}$ & $95.10 \mathrm{a}$ & $95.70 \mathrm{a}$ & $87.96 \mathrm{bc}$ & $83.47 \mathrm{~cd}$ & $83.46 \mathrm{~cd}$ \\
Dry weight $(\mathrm{g})$ & $12.52 \mathrm{bc}$ & $12.44 \mathrm{bc}$ & $12.21 \mathrm{~cd}$ & $12.69 \mathrm{bc}$ & $13.00 \mathrm{a}$ & $12.75 \mathrm{ab}$ & $12.55 \mathrm{bc}$ & $12.76 \mathrm{ab}$ & $12.45 \mathrm{bc}$ \\
\hline
\end{tabular}

Note: Columns with different lowercase letters: Low-temperature plasma treatment on Alexander Summer Squash bud potential, germination rate, significant differences in germination index $(\mathrm{P} \leqslant 0.05)$

90 days after seeds treated by LTP, almost all the intensities $(60-200 \mathrm{~W})$ could increase the shoot $\&$ root length, green $\&$ dry weight and the fiber root number also increased.

It is clear that in the case of an ordinary plant leaf area will increase as growth proceeding, and with increasing leaf area the rate of production of material by assimilation will also increase, this will also lead to higher yield. LTP treatment has a great value of using and spreading on crop production, and the optimal treatment intensity for forage maize seeds was $120 \mathrm{~W}$.

\section{Acknowledgment}

Financial support from National High Technology Research and Development Program 863(2012AA10A505) and China Agriculture Research System (CARS-35) is gratefully acknowledged.

\section{References}

1 Hao Xuejin,Qin Jianguo. Preliminary study on low temperature plasma treatment of seed [J].Journal of Shanxi Agricultural Sciences, 1998, 26(2): 39-41. (in Chinese)

2 Li Ruifu. Plasma machine seed treatment technology[J]. North Rice , 2010, (4)4:52 - 53 . (in Chinese) 
3 Yin, Meiqiang. Research of magnetized arc plasma on seeds biological effects [D]. Dalian: Dalian University of Technology, 2006. (in Chinese)

4 Zhang Yuhang, Zhang Jinglou,Wang qingfa. The application of physical methods in sugar beet seed treatment[J]. China Beet and Sugar, 2005, (2): 20 - 22 . (in Chinese )

$5 \mathrm{Xu}$ Zhiying, Chen Bo,Wei zhen. Various seed treatments on corn yield[J]. Agricultural science \& technology and Equipment, 2011, (4): 15 - 16. (in Chinese)

6 Liu Shan, Ouyang, Xirong,Nie rongbang. Application status and development trend of the physical methods in the crop seed treatment[J]. Crop research, 2007,(2)） 5: 520 - 524 . (in Chinese)

7 Shao Changyong, Wang Decheng,Tang xin, et al. Arc plasma system and its application \& development treads on pre-sowing seeds treatment[J]. China seed industry, 2012, (8):1-3. (in Chinese)

8 Hu Lianglong, Tian Lijia, Hu zhichao,et al. Application of physical agriculture techniques in cleaned seeds treatments[J]. Journal of Anhui agricultural science, 2007, (3)13:3778- 3779. (in Chinese)

9 Yin Meiqiang, HuangMingjing. Stimulatnig Effects of Seed Treament by Magnetized Plasma on Tomato Growth and Yield. Plasma Science \& Technology, 2005, (7)6: 3143-3147.

10 Irina Filatova,Viktor Azharonok,Mikhail Kadyrov.Rf and Microvawe Plasma Application for Pre-Sowing Caryopsis Treatments. Publ Astron Obs. Belgrade No. 89 (2010), 289-292

11 Shao Changyong,Fang Xianfa,Tang Xin,et al. Stimulating effects of low-temperature plasma on seed germination characteristics of green Chinese onion[J]. Transaction of the Chinese Society for Agriculture Machinery, 2013, （06）:

$12 \mathrm{Fu}$ Sanling, Zhang Fu,Li jianchang,et al. Several physical techniques in agriculture and Prospects[J]. Agricultural Mechanization Research, 2006, (1) ) :36- 38. (in Chinese)

13 Shi Yuhai, Fang Xiangqian, Xu dongheng,et al. Effect of plasma treatment of soybean seed with different radiation intensity on biological traits, yield and economic output[J]. Journal of Jilin agricultural sciences, 2010, (35) 6: 6-7. (in Chinese)

14 Luo Haiyun, Ran Junxia, Wang Xinxin, et al. Comparision Study of Dielectric Barrier Discharge in Inert Gases at Atmospheric Pressure[J] . High Voltage Engineering,2012,(38)5:1070-1077

15 Zeng Qingling, Liang Chanjuan, Shen Dongxing, et al. Effects of Acid Rain on Seed Germination of Various Acid Fastness Plants[J] . Journal of Agro-Environment Science, 2004, 23 (1) : 39-42

16 Niu Donghai, Sun Zhian, Yu Fujing, et al. Primary report on effects of plasma on maize[J] . Journal of farm and cuiture, $2011, \quad(1): 43-44$

17 Yu Fang, Zhang Rong, Zhang Pizhi, et al. Effects of plasma on maize[J]. Agricultural Technology \&Equipment, 2008, 
148(4):29-31.

18 Chai Shoutao, Fang Xiangqian, Fu Xihou, et al. Effects of plasma on maize[J]. Modern agricultural science, 2007,(23):138-138.

19 Fa Xiangqian, Bian Shaofeng, Xu Kezhang, et al. Study on Maize Seeds Treated with Plasma to Influence Biological Properties and Yield of Maize[J]. Journal of Maize Sciences,2004,12(4):060-061

20Du Hong, Liu Songtao, Zhao Wei, et al. Effects of plasma on old maize[J]. China seed industry, 2011,(supplement):22-23. 
$\overline{ }$ 
$\overline{ }$ 